\title{
Effect of bacteria type and sucrose concentration on levan yield and its molecular weight
}

\author{
Álvaro González-Garcinuño, Antonio Tabernero, José Ma Sánchez-Álvarez, Miguel A. Galán \\ and Eva M. Martin del Valle*
}

\begin{abstract}
Background: Levan has been traditionally produced from microorganism. However, there is a continuous effort in looking for new strains that improve levan production yield and uses alternative sugar sources for growth. Despite having a wide range of data about levan yield, there are not papers which allow controlling molecular weight, and that plays an essential role for further applications.

Results: The effect of the sucrose concentration on levan yield (and its molecular weight) from Bacillus atrophaeus and Acinetobacter nectaris (Gram positive and Gram negative respectively) was studied in this work. It was found that A. nectaris growth (from 3 to $1.5 \mathrm{~g} \mathrm{~L}^{-1}$ in $40 \mathrm{~h}$ ) and its levan production (from 3 to $1.5 \mathrm{~g} \mathrm{~L}^{-1}$ ) decreases by increasing sucrose concentration (best results at a concentration of $120 \mathrm{~g} \mathrm{~L}^{-1}$ ) whereas B. atrophaeus growth $\left(3.5 \mathrm{~g} \mathrm{~L}^{-1}\right.$ in $30 \mathrm{~h}$ ) and its levan production (also $3.5 \mathrm{~g} \mathrm{~L}^{-1}$ ) were not affected by modifying that parameter. Levan molecular weight from A. nectaris decreases by increasing sucrose concentration (from 8000 to $2000 \mathrm{kDa}$ ) whereas levan molecular weight from $B$. Atrophaeus remains always around $50 \mathrm{kDa}$. By performing a kinetic study, it was shown that $A$. nectaris growth follows a substrate-inhibition model, whereas Monod equation provided a good fit for $B$. atrophaeus growth. Finally, wastes from orange juice industry were used as a medium culture to cultivate those microorganism, obtaining good results with $B$. atrophaeus (growth $3 \mathrm{~g} \mathrm{~L}^{-1}$ in $30 \mathrm{~h}$ ).
\end{abstract}

Conclusions: Levan production kinetics was determined and compared between different bacteria types.

Keywords: Levan, Molecular weight, Kinetics, Byproducts

\section{Background}

Levan is a homopolysaccharide of fructose units which is produced by some plants and microorganisms. These organisms have an enzyme called levansucrase (EC.2.4.1.10), which breaks the sucrose bond between glucose and fructose, and after that, polymerizes these fructoses linked $\beta(2 \rightarrow 6)$. Levan is considered as an exopolysaccharide (EPS), because it is synthesized outwardly the cell. Levansucrase is translated from its respective mRNA in cell cytosol and is secreted to

*Correspondence: emvalle@usal.es

Department of Chemical Engineering, University of Salamanca, Plza. Los Caidos s/n, 37007 Salamanca, Spain bacterial peptidoglycan wall at acid $\mathrm{pH}(5-6)$ where it catalyzes the reaction described above [1].

Levan is a non-typical biopolymer because it is formed by furanoses units (fructose), whereas other biopolymers are formed by pyranoses residues. This fact could have an incredibly interest for different applications such as industry, cosmetics, medicine or nanotechnology [2].

Levan has been traditionally obtained from microorganisms. Zymomonas mobilis, a Gram negative bacterium, is considered the most common microorganism for that matter. However, Z. mobilis produces ethanol at the same time, so a subsequent step is needed for levan purification. The other well-known bacterium for levan production is Bacillus subtilis, which has been extensively studied. Recently, new genera like Hallomonas or 
Pseudomonas have been used for levan production [3, 4]. In total, more than 50 studies have been performed with the aim of analyzing bacteria for levan production [1].

Those studies were focused on optimizing the medium culture in terms of $\mathrm{pH}$, temperature, use of substrates, etc. As an example, Silbir et al. [5] used Z. mobilis strain B-14023 for levan production. These authors presented yeast extract as the most promising nitrogen source for levan production. Another example is the study published by Ing-Lung et al. [6], where temperature, culture time and $\mathrm{pH}$ are considered for levan production with $B$. subtilis (natto). Ing-Lun et al. [7] also studied the effect of sucrose concentration on levan production, obtaining the best results between 200 and $300 \mathrm{~g} \mathrm{~L}^{-1}$. However, none of these articles took into account the effect of the different medium culture in the polymer properties, such as molecular weight.

Nonetheless, there is not a study that explains the role of the bacteria type in levan production (e.g. differences between Gram negative and Gram positive bacteria) and although there are some articles reporting the kinetics of the levan production [8], to the best of our knowledge those kinetics have not been mathematically modelled and as a consequence they have not been fully investigated.

In addition, some studies such as Nicholson et al. [9] reported an important link-up between molecular weights and some polymer properties like melt viscosity, tensile strength, resistance to heat and corrosion properties. These properties could be really interesting for the applications described above such as biomedicine or food. As an example, levan antitumour activity depends on the molecular weight, obtaining a maximum antitumour inhibition for a viscosity molecular weight around 210,000 kDa [10]. Moreover, Elvassore et al. [11] suggested that higher PEG-PLA molecular weight of polymer PEG-PLA, produces a worse drug encapsulation efficiency as well as affecting the drug release. Specifically, a low polymer molecular weight involves a slow and constant drug release.

Furthermore, it is essential to investigate new trends for levan production in order to reduce costs. One of the possible options is the use of cheaper sources as alternative substrates. As an example, Roberto de Oliveira et al. [12] used some regional residuals (sugar cane syrups and sugar cane molasses) as a carbohydrate sources up to a sucrose concentration of $250 \mathrm{~g} \mathrm{~L}^{-1}$ to produce levan. However, wastes from fruit industry (that can be a proper alternative) have not been used yet as an alternative to protein sources (such as yeast extract).

Based on the above-mentioned facts, the main aims of this article are to study the effect of the different type of bacteria and the sucrose concentration on levan production and its molecular weight as well as modelling the kinetics involved in this biopolymer production process. Besides, a new substrate source (a food industry waste) is tested as an alternative culture medium.

In order to do that, two new strains (Bacillus atrophaeus and Acinetobacter nectaris), which have not been used before for levan production, were selected for this study. One of them is a Gram positive bacteria and the other is a Gram negative. Therefore, by using new experimental data and by performing a comparison of our results with some results from literature, the effect of the bacteria type on the polymer molecular weight may be explained. These strains were, in addition, selected in order to find new strains for producing levan as well as for identifying if an original Spanish isolated bacterium (A. nectaris) can be used for that purpose.

Moreover, the effect of the sucrose concentration in levan yield and its molecular weight was studied by modifying the amount of sucrose in the culture medium. Growth and levan yield results were in addition mathematically modelled in order to define the kinetics type followed by the studied bacteria. Finally, wastes from the orange juice industry were tested as an alternative source of proteins for producing levan, indicating the possibility of using food industry residuals to grow microorganisms for biopolymer production.

\section{Methods}

\section{Microorganisms and culture medium}

Two bacteria strains were selected from Spanish microorganism collection culture (CECT). Specifically, $B$. atrophaeus (CECT 0038) as a Gram negative bacteria and A. nectaris (CECT 8127) as a Gram positive bacterium. The last one was isolated from nectar in wild Mediterranean insect-pollinated plants at Doñana Park in Huelva (Spain).

Both strains were cultured in flask recipients (volume $250 \mathrm{~mL}$ ), using the following culture media: $7 \mathrm{~g} \mathrm{~L}^{-1}$ yeast extract, $2.5 \mathrm{~g} \mathrm{~L}^{-1} \mathrm{~K}_{2} \mathrm{HPO}_{4}, 1.6 \mathrm{~g} \mathrm{~L}^{-1} \mathrm{NH}_{4} \mathrm{SO}_{4}, 0.4 \mathrm{~g} \mathrm{~L}^{-1}$ $\mathrm{MgCl}_{2}$. After that, the $\mathrm{pH}$ was adjusted between 5.5 and 6 (with $\mathrm{HCl} 1 \mathrm{M}$ ). Experiments were carried out at $30^{\circ} \mathrm{C}$ and a stirring speed $150 \mathrm{rpm}$ [6].

Furthermore, in order to reduce the medium cost, a byproduct from the juice industry (juice pulp after oranges squeezing process) was used to cultivate the previous microorganisms. That pulp was heated at $90{ }^{\circ} \mathrm{C}$ in water in order to extract nutrients from it, and after that, that liquid was filtered to remove the remaining solids. A source of inorganic nitrogen (ammonium nitrate at $\left.1 \mathrm{~g} \mathrm{~L}^{-1}\right)$ and sucrose $\left(120 \mathrm{~g} \mathrm{~L}^{-1}\right)$ were added to that liquid in order to achieve all the required nutrients.

Since the composition of the juice pulp is unknown, that waste was previously analyzed by elemental 
microanalysis in order to know its chemical composition in carbon, hydrogen, nitrogen, oxygen and sulfur. This analysis procedure is given in "Levan molecular weight determination".

\section{Biomass determination and levan production}

Biomass could be determined by following the solids in suspension method proposed by Xin et al. [13]. This spectrophotometric technique consists of measuring the absorbance of the biomass at $650 \mathrm{~nm}$. In this context, the following equations were obtained to calculate the biomass for both strains (Eqs. 1, 2):

$$
\begin{aligned}
& \text { For A. nectaris: } \mathrm{y}=0.1091 \mathrm{x}-0.0216 \\
& \text { For B. atrophaeus: } \mathrm{y}=0.1049 \mathrm{x}-0.0089
\end{aligned}
$$

where $\mathrm{y}$ is the absorbance at $650 \mathrm{~nm}$, and $\mathrm{x}$ is biomass concentration expressed in $\mathrm{mg} / \mathrm{mL}$.

Using these equations, biomass was measured each $8 \mathrm{~h}$ in order to control cell density and microorganism growth.

At the same time, levan could be estimated by the spectrophotometric method proposed by Vigants et al. [14] at $400 \mathrm{~nm}$. This technique takes advantage of the change of turbidity (at $25^{\circ} \mathrm{C}$ ) in the culture medium due to the levan formation. The procedure is based on the extraction of an aliquot from the flask (each $8 \mathrm{~h}$ ) that must be centrifuged at $10,000 \mathrm{rpm}$ during $10 \mathrm{~min}$ to eliminate biomass. After that, the absorbance was measured at $400 \mathrm{~nm}$. As a result, an equation (Eq. 3) was obtained to determine the levan concentration in our culture medium:

$$
\mathrm{y}=0.1645 \mathrm{x}-0.035
$$

where $\mathrm{y}$ is the absorbance at $400 \mathrm{~nm}$, and $\mathrm{x}$ is levan concentration expressed in $\mathrm{mg} / \mathrm{mL}$.

Furthermore, the amount of glucose consumed for levan synthesis could be estimated using the Eq. 4 [15].

$$
\mathrm{M}_{\text {glucose }}=(180 / 162) \cdot \mathrm{M}_{\text {levan }}
$$

\section{Biomass recovery and levan isolation}

When the culture reaches its stationary phase, biomass is collected and extracted from the medium culture by centrifugation at 10,000 rpm during $10 \mathrm{~min}$. This biomass is discarded, since the levan will be secreted in the supernatant phase. With the aim of extracting and isolating the biopolymer, the following process will be used:

Firstly, pH was adjusted between 9.5 and 10.5 with $\mathrm{KOH} 0.1 \mathrm{M}$ in order to stop the enzymatic reaction for levan production. After that, $1 \mathrm{~mL} \mathrm{CaCl}_{2}(1 \% \mathrm{w} / \mathrm{w})$ was added each $20 \mathrm{~mL}$ of supernatant [4], following by the addition of ethanol $96 \%(\mathrm{v} / \mathrm{v})$ in proportion ethanol: supernatant 3:1. Finally, the resulting mixture is frozen at $-20{ }^{\circ} \mathrm{C}$. After $25 \mathrm{~h}$, the levan precipitates and by a centrifugation process $(6000 \mathrm{rpm}$ during $10 \mathrm{~min})$ the polymer is isolated.

After that, a dialysis process was performed to purify the polymer. Basically, levan was dissolved in deionized water and the dissolution was dialyzed against ultrapure water (ultrapure water was changed two times after $24 \mathrm{~h}$ ) by using cellulose membranes (Orange Scientific, Belgium) with porous size $(12-14 \mathrm{kDa})$. This porous size was chosen with the aim of removing low molecular weight substances such as proteins, nucleic acids or other organic compounds that could be presented in culture media.

The solution was collected after dialysis, and was lyophilized by Telstar Lyophilizaer at $-55^{\circ} \mathrm{C}$ and 0.020 bar in order to remove water and obtain the polymer as a solid product.

\section{Polymer structure determination}

Infrared spectrum (IR) and nuclear magnetic resonance (NMR) were carried out in order to determine the nature of the polymer extracted from culture broth.

FT-IR spectra were recorded in a Perkin-Elmer Spectra ONE instrument, using KBr pellets; 32 spectra (recorded with a nominal resolution of $4 \mathrm{~cm}^{-1}$ ) were averaged to improve the signal-to-noise ratio.

Nuclear magnetic resonance spectra were recorded on a 200 and $400 \mathrm{MHz}(1 \mathrm{H})$ and 50 and $100 \mathrm{MHz}(13 \mathrm{C})$ spectrometers by using a Varian Mercury $200 \mathrm{MHz}$. FTIR spectra were recorded as films. HRMS spectra were recorded by using Q-TOF using electrospray ionization.

\section{Elemental microanalysis of biomass and orange wastes}

In order to define the elemental composition of some substances (biomass or juice byproducts), the analysis of those products was performed by using a modified method from Pregl and Dumas (dynamic flash combustion). This method establishes a relative proportion for Carbon, Hydrogen, Nitrogen and Sulfur; determining Oxygen by difference.

Samples are encapsulated into a tin or silver vial and oxygen is injected into the vial. After that, the vial is placed in an oven at high temperature to produce combustion. Products from this combustion are: $\mathrm{CO}_{2}, \mathrm{H}_{2} \mathrm{O}$, $\mathrm{NO}_{\mathrm{x}}$ and $\mathrm{SO}_{\mathrm{x}}$. These gases are transported along a pipe using Helium as carrier gas, finishing into an oxidationreduction pipe. Finally, gases flow through a non-dispersive infrared detector with the aim of determining $\mathrm{H}_{2} \mathrm{O}$, $\mathrm{CO}_{2}$ and $\mathrm{SO}_{2}$ concentration. $\mathrm{N}_{2}$ is measured by thermal conductivity. 


\section{Levan molecular weight determination}

Molecular weight was determined by static light scattering (SLS) with Zsizer Nano (Malvern instruments). This method is a non-invasive technique that can be used to characterize molecules in a solution. Particles in the sample are illuminated by a light source such as laser, with the particles scattering the light in all directions. MW is determined by measuring the sample at different concentrations and applying the Raleigh equation (Eq. 5), which describes the intensity of light scattered from a particle in solution.

$$
\frac{K \cdot C}{R_{\theta}}=\left(\frac{1}{M_{w}}+2 A_{2} C\right) P_{\theta}
$$

where $\mathrm{K}$ is an optical constant which depends on laser wavelength, solvent refractive index and the differential refractive index increment. $R_{\theta}$ is the Raleigh ratio and $P_{\theta}$ is the angular dependence of the sample scattering intensity. $\mathrm{Mw}$ is molecular weight for the sample. $\mathrm{A}_{2}$ is the second virial coefficient; and $C$ is the concentration. To determine the second virial coefficient and the molecular weight, samples with different polymer concentrations were analyzed by SLS. MW was determined as the interception of Y-axis whereas the slope is related with 2nd virial coefficient.

It is important to specify that this technique needs a standard compound with a well-known behavior in terms of SLS molecular weight determination. In this context, toluene was chosen because it is the most used compound for this purpose.

\section{Growth kinetics equation determination}

Kinetics for microbial growth could be estimated using an unstructured kinetic model, where the specific growth rate $(\mu)$ is determined by using the differential Eq. 6 .

$$
\frac{d x}{d t}=(\mu-D) x
$$

where $\mathrm{dx} / \mathrm{dt}$ is the biomass increment with time, $\mathrm{x}$ is biomass concentration at each time, and $\mu$ is the specific growth rate.

In this case, $\mathrm{D}$ (dilution rate) is considered null because the experiments were performed at batch scale.

Furthermore, biomass results were adjusted to models based on Monod Model [16]. Product rate is calculated following the Eq. 7.

$$
R_{p}=\frac{1}{x} \frac{d p}{d t}
$$

where $\mathrm{Rp}$ is product rate, $\mathrm{x}$ biomass density, and $\mathrm{dp} / \mathrm{dt}$, the variation in product concentration with the time.

Moreover, it was studied if levan production could be adjusted to Luedeking-Piret model [17] (product formation is associated to microbial growth). LuedekingPiret model is described in Eq. 8.

$$
R p=\beta_{x p} \cdot \mu+m_{p}
$$

where $\beta_{x p}$ relates product with biomass, $\mathrm{m}_{\mathrm{p}}$ is the maintenance coefficient (or ATP coefficient), $\mathrm{Rp}$ is product rate and $\mu$ is the specific growth rate

On the other hand, stoichiometric coefficients were determined in order to complete the reaction general equation (Eq. 9):

$$
\begin{aligned}
& \mathrm{CH}_{1.83} \mathrm{O}_{0.91}+\alpha \mathrm{O}_{2}+\beta\left(\mathrm{NH}_{4}\right)_{2} \mathrm{SO}_{3} \\
& \quad \rightarrow \gamma \mathrm{CH}_{x} \mathrm{O}_{y} \mathrm{~N}_{z}+\delta \mathrm{CH}_{1.77} \mathrm{O}_{0.88}+\varepsilon \mathrm{CH}_{2} \mathrm{O}+\omega \mathrm{CO}_{2}
\end{aligned}
$$

this reaction corresponds to:

Sucrose + oxygen + ammonium sulfate $\rightarrow$ biomass + levan + (glucose + fructose $)+$ carbon dioxide

It is assumed that yeast extract is only used for essential amino acids uptake, and it has no contribution in mass balance.

\section{Results}

Results are organized in the following way. Firstly, "Influence of substrate concentration in biomass growth and its kinetic study" and "Influence of substrate concentration in levan production and its kinetic study" describe the effect of the substrate concentration in biomass growth and levan production. The kinetic study is also included in each respective section.

Levan characterization is explained in "Levan characterization", whereas the effect of the sucrose concentration on the molecular weight is studied in "Influence of substrate concentration in levan molecular weight for both strains". On the other hand, experimental and kinetics studies of how glucose inhibits the levan yield are performed in "Levan inhibition with glucose". Finally, the use of a waste product as a medium culture for producing levan is proposed in "Wastes from juice factories as a substrate for cultivating both strains".

\section{Influence of substrate concentration in biomass growth and its kinetic study}

Different concentrations of sucrose were added to the microorganism culture medium. Specifically, experiments were carried out with 120, 150, 180, 210, 240 and $270 \mathrm{~g} \mathrm{~L}^{-1}$ sucrose for both strains. Those concentrations have been used previously in different articles [7, 12]. Biomass and levan were determined each $8 \mathrm{~h}$ following the methods already described in the experimental section. The $\mathrm{pH}$ remained between 5.5 and 6 because an acid medium is needed to secrete the levansucrase to the bacterial cell wall. 
Growth results are shown at Fig. 1. Graph A belongs to biomass growth for $A$. nectaris and Graph $B$ belongs to $B$. atrophaeus results.

As can be observed in Fig. 1a (for A. nectaris), biomass proliferation decreased with the sucrose (from 3.0 with $120 \mathrm{~g} \mathrm{~L}^{-1}$ of sucrose to $2.0 \mathrm{~g} \mathrm{~L}^{-1}$ with more than $180 \mathrm{~g} \mathrm{~L}^{-1}$ of sucrose). However, for B. atrophaeus, the sucrose did not produce a significant effect on the microorganism growth (Fig. 1b) and the biomass growth ranged from 3.0 to $4.0 \mathrm{~g} \mathrm{~L}^{-1}$. It can be concluded that the best sucrose concentration was around $120 \mathrm{~g} \mathrm{~L}^{-1}$ for $A$. nectaris (biomass growth around $3 \mathrm{~g} \mathrm{~L}^{-1}$ in $30 \mathrm{~h}$ ) whereas the optimum value was around $180 \mathrm{~g} \mathrm{~L}^{-1}$ for $B$. atrophaeus (biomass growth around $4 \mathrm{~g} \mathrm{~L}^{-1}$ in $30 \mathrm{~h}$ ).

After determining biomass proliferation, the microorganism growth kinetics was studied. As was described before, $A$. nectaris may follow a typical substrate-inhibition kinetic (Eq. 10 [18]).

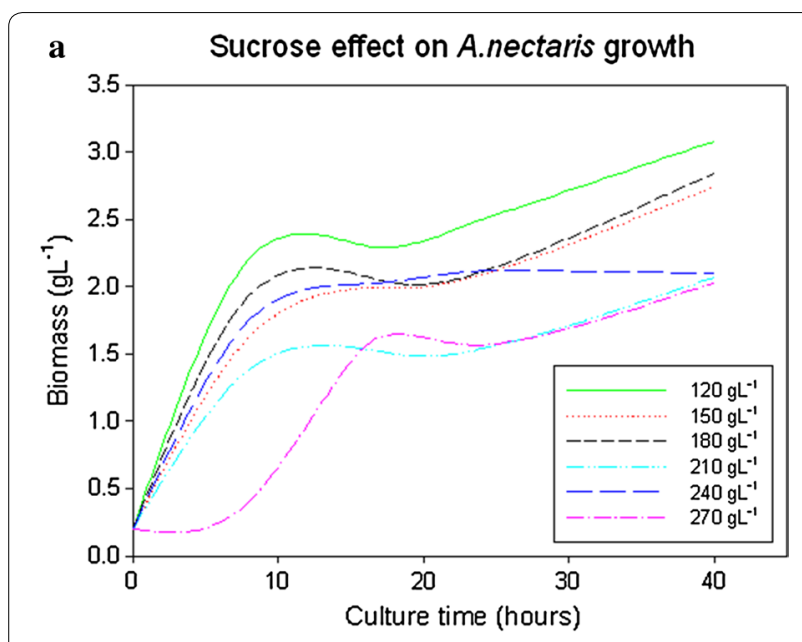

b Sucrose effect on B. atrophaeus growth

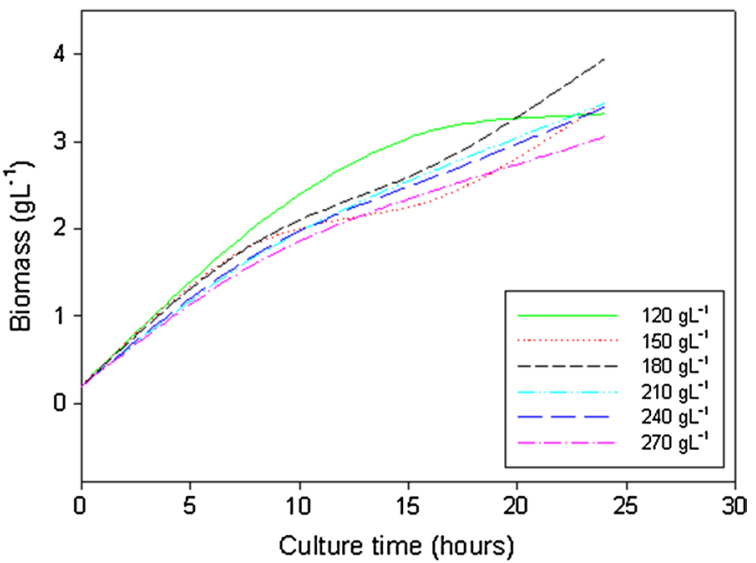

Fig. 1 Sucrose concentration effect on microbial growth. a Effect on A. nectaris. b Effect on B. atrophaeus

$$
\mu=\mu_{\max } \frac{S}{\frac{S^{2}}{K i}+S+K_{s}}
$$

The following kinetic coefficients were obtained by fitting experimental data-theoretical data: $\mu_{\max }: 3.207 \mathrm{~h}^{-1}$, Ks: $2068 \mathrm{~g} \mathrm{~L}^{-1}$, Ki: $9.73 \mathrm{~g} \mathrm{~L}^{-1}$.

The classical Monod model was used for fitting the experimental data with $B$. atrophaeus (without sucrose inhibition). A good correlation coefficient $\left(R^{2}>0.90\right)$ was obtained, whereas the kinetic parameters are: $\mu_{\max }$ : $0.107 \mathrm{~h}^{-1}$, Ks: $5.48 \mathrm{~g} \mathrm{~L}^{-1}$.

\section{Influence of substrate concentration in levan production and its kinetic study}

While cultivating both bacteria, the levan produced was determined each $8 \mathrm{~h}$, using the spectrophotometric method described above. Results for both strains are illustrated in Fig. 2.

Levan production and biomass proliferation follow the same tendency. Levan production from $A$. nectaris

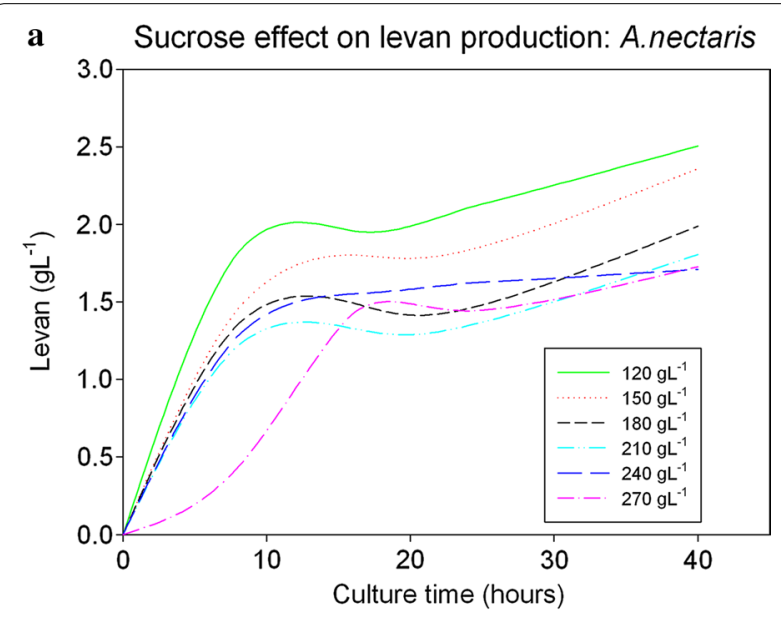

b Sucrose effect on levan production: B. atrophaeus

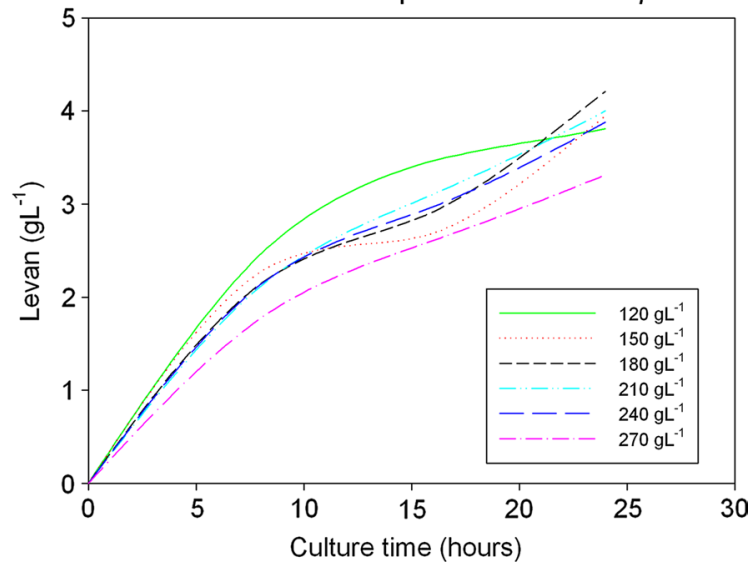

Fig. 2 Sucrose concentration effect on levan synthesis. a Effect on $A$. nectaris; b effect on B. atrophaeus 
decreases by increasing sucrose concentration (from 2.5 at $120 \mathrm{~g} \mathrm{~L}^{-1}$ of sucrose to 1.5 with $270 \mathrm{~g} \mathrm{~L}^{-1}$ of sucrose). On the other hand, there was not a clear effect of sucrose concentration on $B$. atrophaeus levan yield (between 3.0 and $4.0 \mathrm{~g} \mathrm{~L}^{-1}$ for all sucrose concentrations in the medium). That is, sucrose concentration inhibited levan production in Gram negative bacteria, but it had no effect on Gram positive bacteria.

Assuming that levansucrase follows the well-known Michaelis-Menten kinetic equation [19]; parameters $V m a x$ and $K m$ were determined for both strains by fitting experimental to theoretical data. For A. nectaris, $V m a x$ and $K m$ vales are: $0.061 \mathrm{~g} \mathrm{~L}^{-1} \mathrm{~h}^{-1}$, and $66 \mathrm{~g} \mathrm{~L}^{-1}$, respectively. For $B$. atrophaeus, Vmax and $K m$ values are: $0.109 \mathrm{~g} \mathrm{~L}^{-1} \mathrm{~h}^{-1}$ and $54 \mathrm{~g} \mathrm{~L}^{-1}$. These results agreed with the inhibition hypothesis for Gram negative strains. $B$. atrophaeus can produce levan two times faster than $A$. nectaris, and substrate specificity was higher for $B$. atrophaeus than for $A$. nectaris (the lowest $K m$ was obtained for $B$. atrophaeus).

With the previous results, it is possible to analyze if levan production is associated with biomass growth. This fact, which has not been studied previously in the literature, must be taken into account for a scale-up. Firstly, it was assumed that levan is associated with biomass proliferation, following Luedeking-Piret equation (Eq. 8).

Luedeking-Piret equation was used for fitting the experimental data for each sucrose concentration for both strains, obtaining the following parameters (Table 1)

Finally, in order to complete the reaction general equations, stoichiometric coefficients were determined as it was explained in kinetics section. For performing mass balances calculation, two initial conditions were determined experimentally: $\beta x p$ that can be calculated as $\delta / \gamma$, that can be calculated from Vigants experiments-Eq. (4). In our case, $\delta=0.562 \mathrm{Cmol}$ levan/Cmol sucrose, whereas $\beta x p$ is taken for each strain after modelling experimental data with Luedeking-Piret equation. Stoichiometric coefficients for both bacteria are indicated in Table 2.

Table 1 Coefficient determination for $\beta \times p$

\begin{tabular}{|c|c|c|c|c|c|}
\hline \multicolumn{3}{|l|}{ A. nectaris } & \multicolumn{3}{|l|}{ B. atrophaeus } \\
\hline [Sucrose] (g/L) & $\beta x p$ & $M_{p}$ & [Sucrose] (g/L) & $\beta x p$ & $M_{p}$ \\
\hline 120 & 6.079 & $-5 E-17$ & 120 & 1.3427 & -0.0004 \\
\hline 150 & 6.079 & $+2 \mathrm{E}-16$ & 150 & 1.3915 & -0.0071 \\
\hline 180 & 6.079 & $+1 E-16$ & 180 & 1.3032 & -0.0069 \\
\hline 210 & 6.079 & $-6 E-17$ & 210 & 1.4255 & -0.0052 \\
\hline 240 & 6.079 & $+2 \mathrm{E}-16$ & 240 & 1.4133 & -0.0059 \\
\hline 270 & 6.079 & $-8 \mathrm{E}-17$ & 270 & 1.2588 & -0.0007 \\
\hline Medium value & 6.079 & $+5.2 \mathrm{E}-17$ & Medium value & 1.3558 & -0.0044 \\
\hline
\end{tabular}

Table 2 Stoichiometric coefficients determined from experimental data (expressed in $\mathrm{Cmol}$ substance/Cmol sucrose)

\begin{tabular}{lll}
\hline & A. nectaris & B. atrophaeus \\
\hline$a$ & 0.02 & $\approx 0$ \\
$\beta$ & 0.0105 & 0.047 \\
$\gamma$ & 0.105 & 0.470 \\
$\delta$ & 0.562 & 0.562 \\
$\varepsilon$ & 0.301 & 0.180 \\
$\omega$ & 0.033 & $\approx 0$ \\
\hline
\end{tabular}

Respiration quotient (RQ), which is defined as quotient between $\alpha$ and $\omega$, could be determined, with the following results: for $A$. nectaris RQ $=1.69$ and for $B$. atrophaeus it was not possible to calculate because both values are aprox. 0 .

\section{Levan characterization}

After levan isolation and purification, several analytical techniques were used to check polymer structure. Figure 3 shows spectrums for levan extracted (A: infrared spectrum, B: H-NMR, C: C-NMR).

These figures confirm the production of levan from the selected strains due to the similarities between the obtained IR spectrum and the different spectra from literature $[4,21]$. Same similarities were found for the nuclear magnetic resonance (NMR) spectra. The six ${ }^{13} \mathrm{C}$ NMR characteristic levan broad signals were at the different ppm $(62.3,64.7,75.1,75.5,79.8,105.9)$. Those signals were described in literature [20].

\section{Influence of substrate concentration in levan molecular weight for both strains}

Levan molecular weight for each strain and at the different sucrose concentrations was determined by static light scattering (SLS). Figure 4 shows the effect of the sucrose concentration on levan molecular weight.

As can be observed, several differences can be found for both strains. A. nectaris molecular weight was higher than the $B$. atrophaeus molecular weight. A. nectaris levan molecular weight ranged 1000$6000 \mathrm{kDa}$, whereas $B$. atrophaeus produced a levan with a molecular weight ranging from 15 to $90 \mathrm{kDa}$. Furthermore, an equation relating $A$. nectaris molecular weight with sucrose concentration $\left(\mathrm{g} \mathrm{L}^{-1}\right)$ was determined (Eq. 11).

$$
y=-37.2 x+11406
$$

where $y$ is the molecular weight in $\mathrm{kDa}$, and $x$ is the sucrose concentration in $\mathrm{g} \mathrm{L}^{-1}$. 

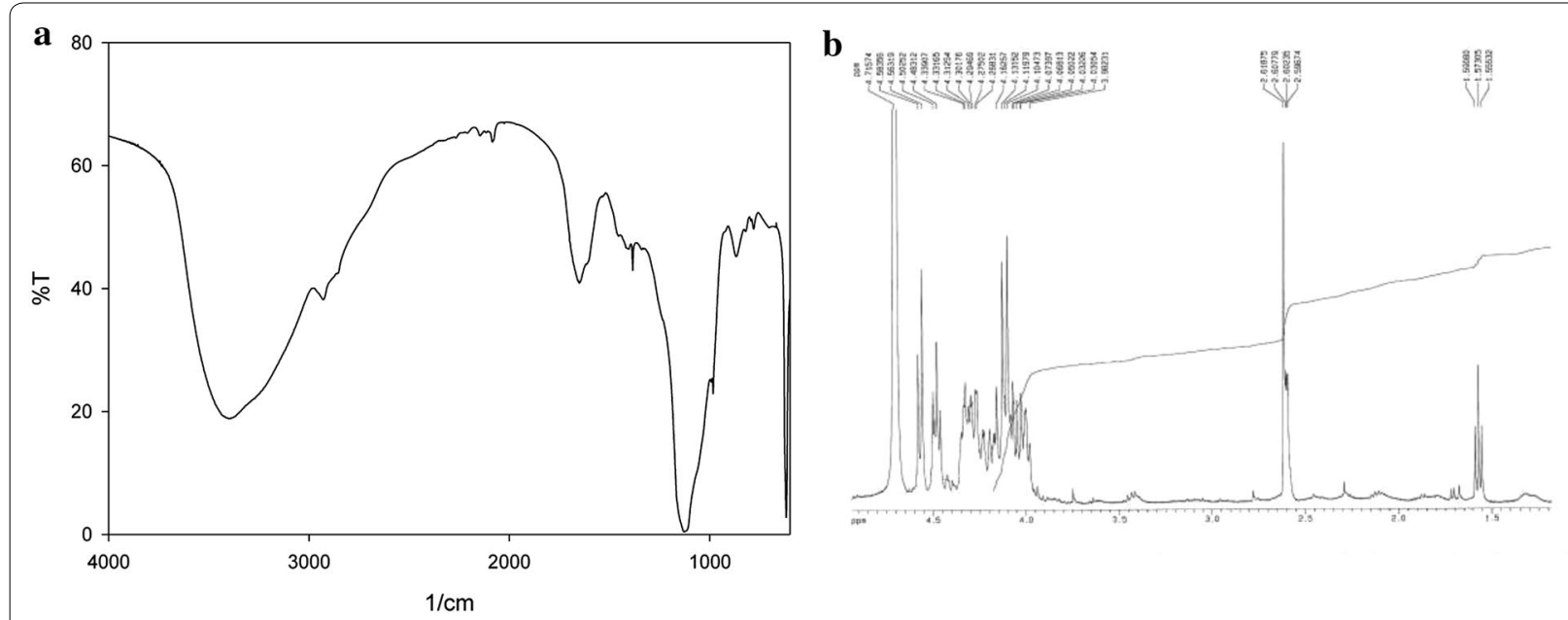

c

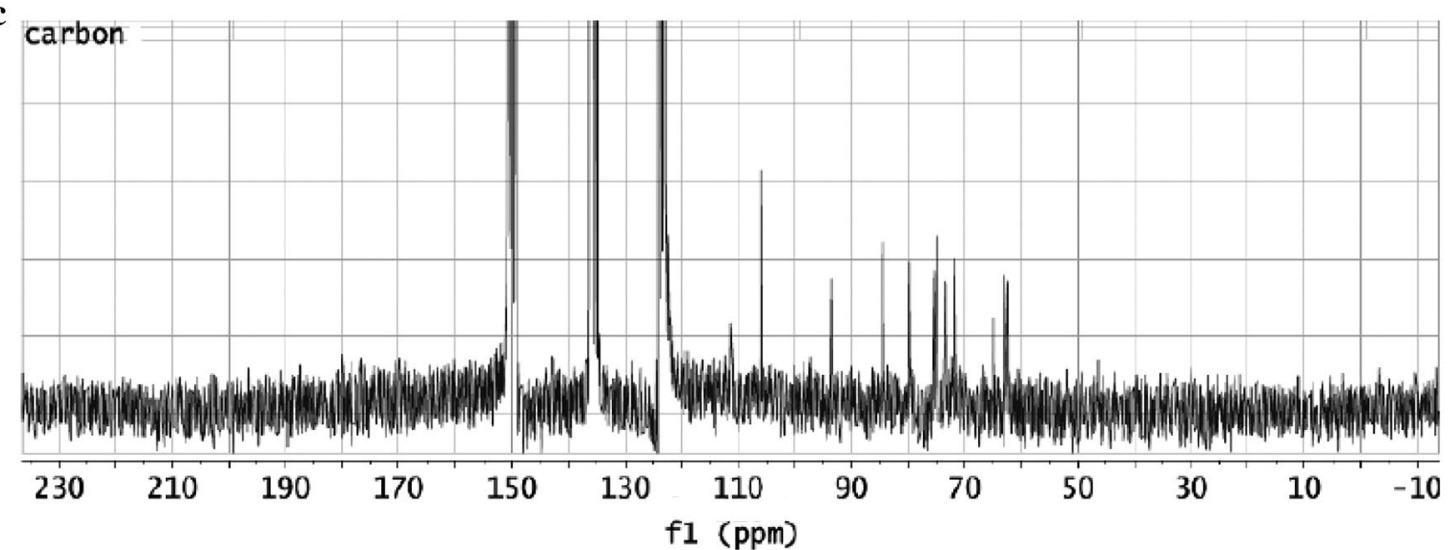

Fig. 3 Characterization of levan obtained. a Infrared spectrum, b H-MRN, c C-MRN

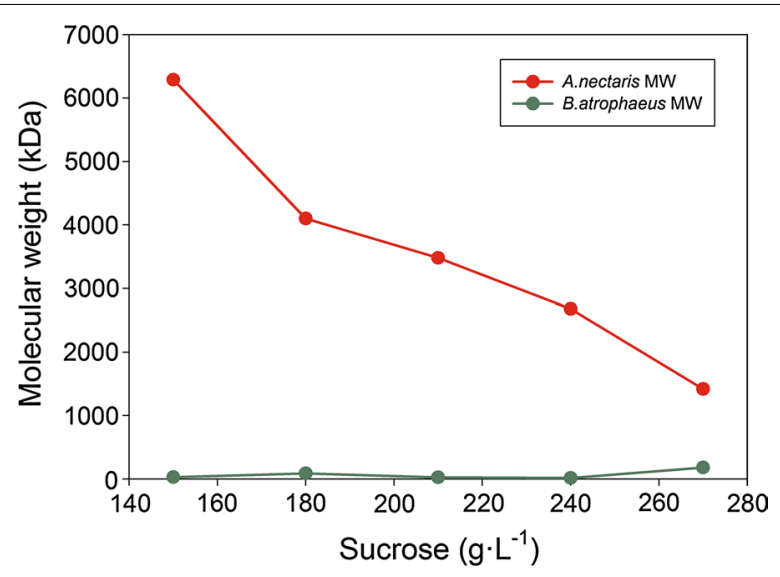

Fig. 4 Levan molecular weight depending on sucrose initial concentration

\section{Levan inhibition with glucose}

Based on the previous results, sucrose can inhibit biomass and levan production in Gram negative bacteria (A. nectaris). However, it is unclear the mechanism of that inhibition. It is well-known [21] that glucose inhibits invertase in Saccharomyces cerevisae. Invertase (EC.3.2.1.26) is an enzyme which catalyzes the sucrose breaking into glucose and fructose, but it does not polymerize that fructose.

Some experiments were performed in order to prove if levansucrase follows a similar mechanism for inhibition. Different concentrations of glucose were added to $A$. nectaris culture medium and levan production was determined. Results are sown in Fig. 5.

As can be seen in Fig. 5, levan production decreased by increasing glucose concentration (ranging from $2.0 \mathrm{~g} \mathrm{~L}^{-1}$ 


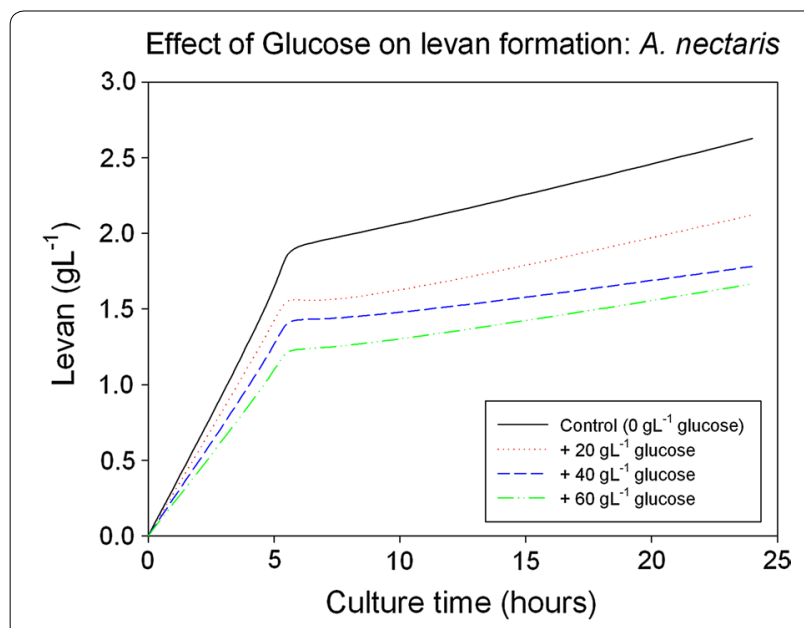

Fig. 5 Effect of glucose on levan formation from A. nectaris

without glucose in the medium to around 1.2 with $60 \mathrm{~g} \mathrm{~L}^{-1}$ of glucose in the medium).

Based on the previous experiments, an equation was obtained to predict the polymer formation depending on the glucose concentration (Eq. 12).

$$
\frac{d p}{d t}=-0.0018[I]+0.3255
$$

where [I] is glucose concentration in g glucose per liter. More data concerning these calculations are included in the Additional files 1, 2.

\section{Wastes from juice factories as a substrate for cultivating both strains}

Acinetobacter nectaris and B. atrophaeus were cultivated with wastes from an orange juice factory. The composition of this residual was analyzed with the aim of determining its molecular formula. After performing the analysis, the molecular formula was $\mathrm{CH}_{1.76} \mathrm{O}_{0.90} \mathrm{~N}_{0.04}$. Due to the low nitrogen value, ammonium nitrate was used as a nitrogen source. That source has been described previously as good nitrogen source for bacteria growth [22]. Also, sucrose was added at $120 \mathrm{~g} \mathrm{~L}^{-1}$ because that concentration provided the highest yield without inhibiting microorganism growth and polymer production. Figure 6 illustrates the results of cultivating both bacteria with this culture medium.

As can be observed in Fig. 6, B. atrophaeus grew in the new culture medium by using wastes from orange juice factories, with a similar growth rate in comparison with the results obtained for the same strain with the common medium (Fig. 1). However, A. nectaris did not grow when wastes are used because these residuals did not provide enough nutrients for that strain. Further studies must be done in order to determine which nutrients have to be added to grow $A$. nectaris.

\section{Bacteria growth on byproducts from juice factories}

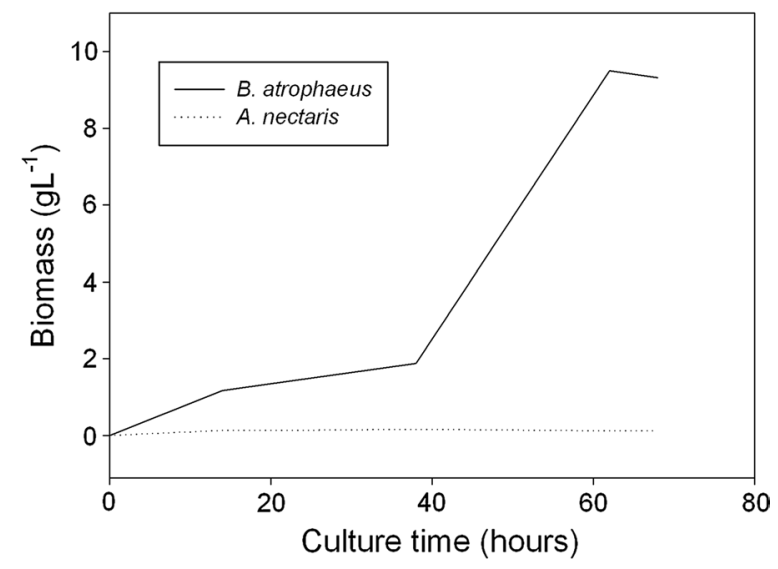

Fig. 6 Bacteria growth on byproducts from juice factories

After that, B. atrophaeus biomass was recovered and the levan was isolated and purified, producing $24.2 \mathrm{~g}$ levan $\mathrm{L}^{-1}$. This value is similar to the result obtained with the common culture medium.

Levan molecular weight obtained from $B$. atrophaeus was $200 \mathrm{kDa}$. This value is approximately two times the levan molecular weight that was synthesized with the common medium. Nevertheless, this molecular weight is still lower than levan molecular weight from $A$. nectaris.

\section{Discussion}

\section{Substrate effect on biomass yield}

The results concerning the effect of substrate (Fig. 1) can be explained depending on the different bacteria type. A. nectaris is a Gram negative bacterium and as consequence the levansucrase can be located at their periplasmic space. On the other hand, B. atrophaeus is a Gram positive strain, so sucrose and enzyme cannot be in contact for a long time, due to the existence of a peptidoglycan wall. Therefore, the inhibition in A. nectaris was produced due to the accumulation in its periplasmic space. This contact can produce enzyme inhibition by substrate. This possible mechanism is illustrated in Fig. 7.

These results agree with the ones that have been proposed previously by Senthilkimar and Gunasekaran [23] with a classical Gram negative bacterium (Zymomonas mobilis). Furthermore, previous results with other Gram positive bacterium (Bacillus subtilis) show that biomass proliferation is independent from sucrose concentration [6].

\section{Substrate effect on levan yield}

The results concerning levan production also confirm the hypothesis described in Fig. 7, where sucrose in periplasmic space does not only inhibit biomass growth but also levan production. 


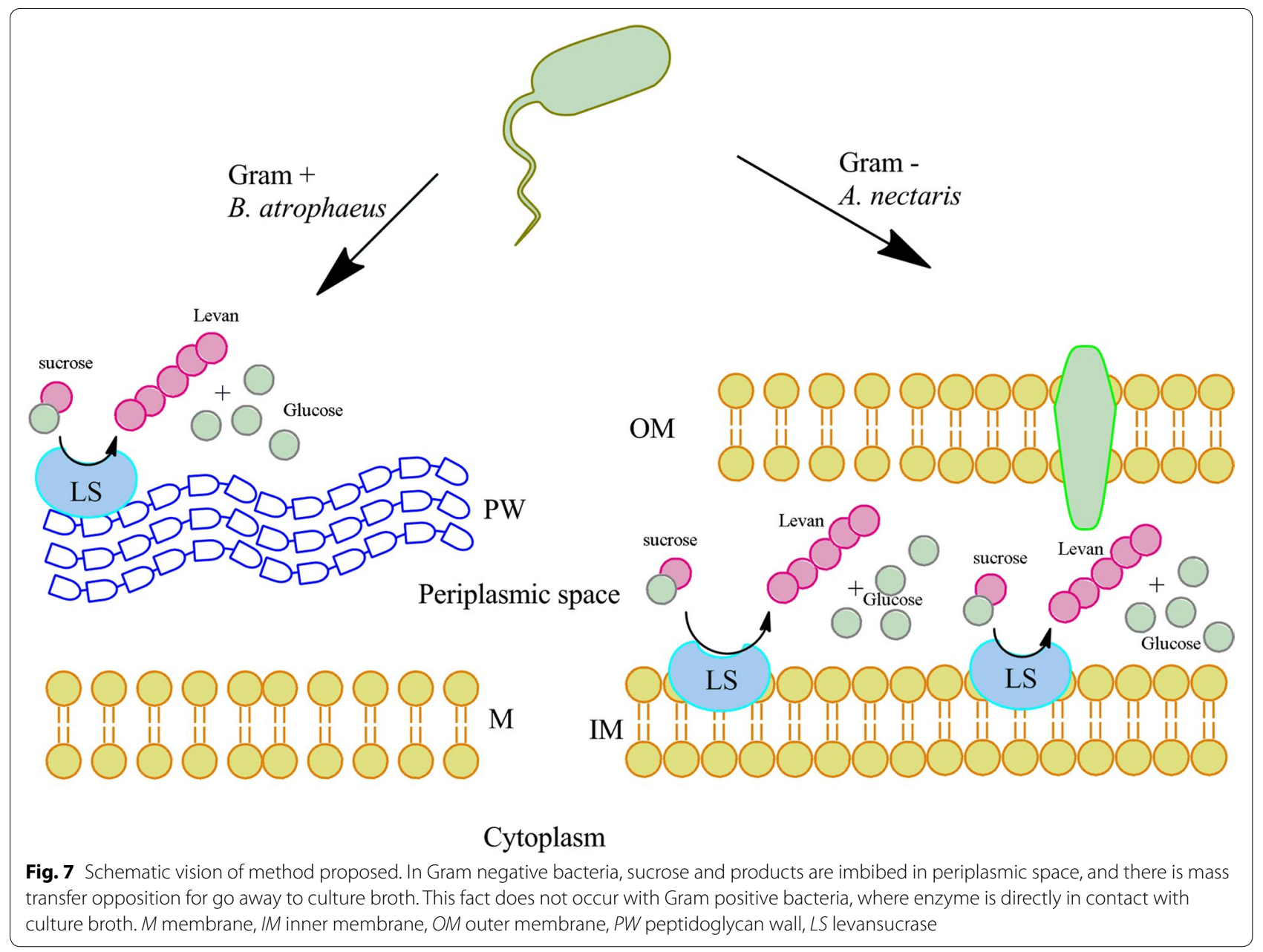

In comparison with literature, it is possible to find strains that produce a similar amount of levan. As an example, B. subtilis (natto) ATTCC 7058 produced $3.6 \mathrm{~g} \mathrm{~L}^{-1}$ in $21 \mathrm{~h}$ [7], 1-2 $\mathrm{g} \mathrm{L}^{-1}$ of levan was produced after cultivating Pseudomonas fluorescens in $30 \mathrm{~h} \mathrm{[4]}$ whereas only around $1 \mathrm{~g} \mathrm{~L}^{-1}$ was obtained after extracting levan from Halomonas sp. AAD6 [3].

From kinetics results (observed in Table 1), it can be concluded that levan production is associated to the biomass growth. A. nectaris showed a better ratio product-biomass than $B$. atrophaeus, meaning that $A$. nectaris produced six times more levan for each biomass gram than $B$. atrophaeus. This fact suggested $A$. nectaris as an effective bacterium for levan production due to its high levan production for a lower biomass proliferation. Obtaining high amounts of levan without requiring a great biomass growth is a good strain quality for a future scale-up process. Moreover, results from Table 2 (RQ) confirm that product formation in $A$. nectaris was more efficient than in $B$. atrophaeus.

\section{Molecular weight}

As it has been mentioned in results chapter, levan molecular weight from A. nectaris can be controlled by sucrose concentration. However, results showed that initial sucrose concentration did not modify levan molecular weight obtained from B. atrophaeus. This fact can be explained due to the cell wall and membrane structure. Levan polymerization in A. nectaris is located the periplasmic space, and as a consequence the polymer experience some difficulties to cross this space towards the culture broth. Therefore, the polymer could remain in the plasmatic membrane and can incorporate new fructose unit, increasing its molecular weight. The previous results highlighted a new possibility for controlling polymer molecular weight by modifying sucrose concentration in the medium culture.

\section{Glucose inhibition}

Results from glucose experiments suggest that glucose may be one of the factors that can be involved in levan inhibition for Gram negative bacteria, and explain why 
an increase of sucrose in the medium (and as a consequence more glucose) inhibits levan production for this type of bacteria. In this context, Eq. [12] can be used as a tool to determine levan and biomass yield depending on the glucose concentration.

\section{Waste from juice factories}

Results from experiments that considered wastes from juice factories, highlight that there is a possibility of reducing the culture medium cost by using an alternative and inexpensive medium, such as residuals from the juice factories.

As a matter of fact, after performing some economic calculations, it is possible to reduce the cost of the medium culture (without considering sucrose) up to an $86 \%$. This reduction ranges from $604 € \mathrm{~m}^{-3}$ (rich medium) to $87 € \mathrm{~m}^{-3}$ (new substrate source). If sucrose price is included, reduction reaches $10 \%$ (from 5000 to $4482 € \mathrm{~m}^{-3}$ ). Considering a four days process, the cost reduction is $129 € \mathrm{~m}^{-3}$ day $^{-1}$. More details regarding these calculations are included in Additional file 2.

Although several works have studied the influence of different parameters $(\mathrm{pH}$, temperature, substrate types and concentration) in levan production, the use of wastes from fruit factories has not been described yet.

\section{Conclusions}

The effect of sucrose concentration and the bacteria type on levan yield and its molecular weight has been studied in this work. Two new strains (A. nectaris and $B$. atrophaeus) were selected and cultivated to synthesize levan. Specifically, they respectively produce around 3 and $3.5 \mathrm{~g} \mathrm{~L}^{-1}$ of polymer. Results indicate that an increase of sucrose concentration decreases levan yield and molecular weight (from 8000 to $2000 \mathrm{kDa}$ ) for $A$. nectaris strain, whereas it does not produce a significant effect on B. atrophaeus growth and levan molecular weight (more or less $50 \mathrm{kDa}$ at all the investigated conditions). The best sucrose concentrations were $120 \mathrm{~g} \mathrm{~L}^{-1}$ for A. nectaris and around $180 \mathrm{~g} \mathrm{~L}^{-1}$ for B. atrophaeus. The difference in those results is explained by taking into account the existence of peptidoglycan wall in Gram positive bacteria. Besides, by modelling growth kinetics, it can be concluded that $A$. nectaris follows a substrate-inhibition kinetics controlled by glucose whereas $B$. atrophaeus follows a typical Monod model. Finally, $B$. atrophaeus is able to grow ( $3 \mathrm{~g} \mathrm{~L}^{-1}$ in $30 \mathrm{~h}$ ) by using a medium culture with wastes from orange juice industry as an alternative culture medium, indicating the possibility of using wastes for growing bacteria with the aim of producing levan.

\section{Additional files}

Additional file 1. Additional material A.

Additional file 2. Additional material B.

\section{Abbreviations}

EPS: exopolysaccharide; PEG-PLA: polyethylene glycol-polylactic acid; CECT: Spanish microorganism collection culture; IR: infrared spectrum; NMR: nuclear magnetic resonance; FTIR: fourier transform infrared spectrum; SLS: static light scattering; MW: molecular weight; $\mu$ : specific growth rate; $\mathrm{D}$ : dilution rate; $\mathrm{x}$ : biomass concentration; t: time; $\mathrm{R}_{\mathrm{p}}$ : product rate; $\mathrm{p}$ : product concentration; $\beta_{x p}$ : Luedeking-Piret coefficient; $m_{p}$ : maintenance coefficient; Ks: monod constant; Ki: inhibition constant; $\vee$ max: maximal velocity; Km: michaelis-menten constant; [l]: inhibitor concentration.

\section{Authors' contributions}

AGG carried out experiment and wrote some sections of the manuscript. AT and JMaSA wrote other sections of the manuscript and supervised the experiments procedure. EMaMdV and MAG designed the experiment, supervise the experiments results and checked the manuscript. All authors read and approved the final manuscript.

\section{Acknowledgements}

The authors want to thank the Inorganic Chemistry Department of the University of Salamanca for his help with the IR experiments.

\section{Competing interests}

The authors declare that they have no competing interests

Consent for publication

All authors consent to publish this manuscript.

Ethics approval and consent to participate

The authors declare that they have no competing interests. This research has the ethics approval and all authors consent to participate.

\section{Funding}

Authors want to acknowledge the funds from the Regional Government of Castilla y León (Spain), project reference SA004U16. Álvaro González-Garcinuño also acknowledges his Ph.D. grant (F.P.U.) from the Spanish Ministry of Education, Culture and Sport (Ref. FPU14/04914).

\section{Publisher's Note}

Springer Nature remains neutral with regard to jurisdictional claims in published maps and institutional affiliations.

Received: 9 January 2017 Accepted: 15 May 2017

Published online: 23 May 2017

\section{References}

1. Srikanth S, Sundhar Reddy CHSS, Siddartha G, Ramaiah MJ, Babu Uppuluri K. Review on production, characterization and applications of microbial levan. Carbohydr Polym. 2015;120:102-14.

2. Gupta SK, Pal AK, Sahu NP, Dalvi RS, Akhtar MS, Jha AK, Baruah SK. Dietary microbial levan enhances tolerance of Labeo rohita (Hamilton) juveniles to thermal stress. Aquaculture. 2010;306:398-402.

3. Poli A, Kazak H, Gürleyendag B, Tommonaro G, Pieretti G, Öner ET, Nicolaus B. High level synthesis of levan by a novel Halomonas species growing on defined media. Carbohydr Polym. 2009;78:651-7. 
4. Jathore NR, Bule MV, Tilay AV, Annapure US. Microbial levan from Pseudomonas fluorescens: characterization and medium optimization for enhanced production. Food Sci Biotechnol. 2012;21:1045-53.

5. Silbir S, Dagbagli S, Yegin S, Baysal T, Goksungur Y. Levan production by Zymomonas mobilis in batch and continuous fermentation systems. Carbohydr Polym. 2014;99:454-61.

6. Ing-Lung S, Yun-Ti Y, Chwen-Jen S, Chien-Yan H. Production and Characterization of Levan by Bacillus subtilis (Natto) Takahashi. J Agric Food Chem. 2005;53:8211-5.

7. Ing-Lung S, Tsaur-Chin W, Shou-Zoo C, Gen-Der L. Sequential production

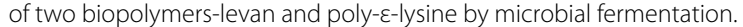
Bioresour Technol. 2011;102:3966-9.

8. Esawy MA, Amer H, Gamal-Eldeen AM, El Enshasy HA, Helmy WA, AboZeid MAM, Malek R, Abo-Zeid MAM, Malek R, Ahmed EF, Awad GEA. Scaling up, characterization of levan and its inhibitory role in carcinogenesis initiation stage. Carbohydr Polym. 2013;95:578-87.

9. Nicholson M, Whitley KS, Gates TS. The combined influence of molecular weight and temperature on the physical aging and creep compliance of a glassy thermoplastic polymide. Mech Time Depend Mat. 2001;5:199-227.

10. Calazans GMT, Lima RC, França FP, Lopes CE. Molecular weight and antitumour activity of Zymomonas mobilis levans. Int J Biol Macromol. 2000;27:245-7.

11. Elvassore N, Bertucco A, Caliceti P. Production of insulin-loaded poly(ethylene glycol)/poly (I-lactide) (PEG-PLA) nanoparticles by gas antisolvent techniques. J Pharm Sci. 2001;90:1628-36.

12. de Oliveira MR, da Silva S RSSF. Study of levan production by Zymomonas mobilis using regional low-cost carbohydrate sources. Biochem Eng J. 2007;37:177-93.
13. Xin L, Hong-ying H, Yang-Jia Y. Lipid accumulation and nutrient removal properties of a newly isolated freshwater microalga, Scenedesmus sp. LX1, growing in secondary effluent. New Biotechnol. 2010;27:59-63.

14. Vigants A, Hicke HG, Marx SP. A simple and efficient Method for the Purification of Membrane-Bound levansucrase from Zymomonas mobilis. Curr Microbiol. 2001;42:415-8.

15. Vigants A, Marx SP, Linde R, Ore S, Bekers M, Vina I, Hicke HG. A novel and simple method for the purification of extracellular levansucrase. Curr Microbiol. 2003;47:198-202

16. Monod J. The growth of bacterial cultures. Annu Rev Microbiol. 1949;3:371.

17. Luedeking R, Piret EL. A kinetic study of the lactic acid fermentation batch process at controlled pH. J Biochem Microbiol Tech Eng. 1959;1:393.

18. Nielsen J, Villadsen J. Bioreaction engineering principles. 2nd ed. New York: Plenum; 1994

19. Kenneth AJ, Roger SG. The Original Michaelis Constant: translation of the 1913 Michaelis-Menten Paper. Biochemistry. 2011;50(39):8264-9.

20. Zhang T, Li R, Qian H, Mu W, Miao M, Jiang B. Biosynthesis of levan by levansucrase from Bacillus methylotrophicus SK 21.002. Carbohydr Polym. 2014;101:975-81.

21. Elorza MV, Villanueva JR, Sentandre R. The mechanism of catabolite inhibition of invertase by glucose in Saccharomyces cerevisae. Biochem Biophys Acta. 1977;475:103-12.

22. Gomaa EZ. Production of PHA by Bacillus subtilis and E.coli grown on cane molasses fortified with ethanol. Braz Arch Biol Technol. 2014;57:1.

23. Senthilkumar V, Gunasekaran P. Bioethanol production from cellulosic substrates: engineered bacteria and process integration challenges. J Sci Ind Res. 2005;64:845-53.

\section{Submit your next manuscript to BioMed Central and we will help you at every step:}

- We accept pre-submission inquiries

- Our selector tool helps you to find the most relevant journal

- We provide round the clock customer support

- Convenient online submission

- Thorough peer review

- Inclusion in PubMed and all major indexing services

- Maximum visibility for your research

Submit your manuscript at www.biomedcentral.com/submit 